\title{
A universidade e uma nova hegemonia
}

Tatiana Carvalho

Mestranda em Educação pela Universidade de São Paulo

\section{Resumo}

Reflete-se aqui sobre o papel da Universidade na atual sociedade capitalista. Ela teria a capacidade de difundir a concepção de mundo das classes trabalhadoras, contribuindo para a construção de uma outra sociedade, ou ela seria mais um instrumento de reprodução das sociedades capitalistas? Existe um conflito contínuo entre essas duas propostas, que se tenta apresentar com base na discussão gramsciana sobre seus conceitos fundamentais, buscando-se compreender a realidade brasileira atual neste contexto. Procura-se também abordar o debate sobre a Universidade no Brasil, analisando-se em que medida seria possível uma atuação transformadora da realidade social por parte desta instituição.

Palavras-chave: Universidade; Hegemonia; Ideologia.

\begin{abstract}
This article presents a reflection on the University in a capitalist society. It would have the capacity to spread out the conception of world of the diligent classrooms, contributing for the construction of one another society, or it would be an instrument of reproduction of the capitalist society? There's a conflict between these two distinct proposals, and I try to present this movement by using the Gramsci's concepts, understanding the current Brazilian reality in this context. I also try to present the current debate on the University in Brazil, trying to understand if it's possible to the University to transform the social reality.
\end{abstract}

Keywords: University; Hegemony; Ideology. 
As pessoas dessas casas vão todas pra universidade Onde entram em caixinhas quadradinhas iguaizinhas Saem doutores, advogados, banqueiros de bons negócios Todos eles feitos de tic tac, todos, todos iguaizinhos. Little Boxes, Malvina Reynolds (versão de Nara Leão)

\section{Introdução}

$\mathrm{E}$ ssa canção de Malvina Reynolds, de 1962, gravada também por Nara Leão em uma versão em português em 1969 no álbum Coisas do Mundo, é muito interessante porque fala sobre os valores de uma determinada camada da sociedade capitalista contemporânea (especialmente aquela que, na época, vivia nos confortáveis subúrbios dos Estados Unidos) e também sobre o conformismo com um certo estado de coisas e com os papéis que, de certa forma, são impostos às pessoas. De modo satírico, a música fala sobre como elas "entram em caixinhas" e "saem todas iguaizinhas", envernizadas com princípios que não são muito discutidos, mas simplesmente adotados, de modo que se garanta a reprodução perpétua de um modo de vida específico e a existência de um tipo de sociedade.

Por outro lado, a canção também chama a atenção para o papel que certas instituições desempenham nesse processo, como a família, por exemplo. Os rapazes formam uma família e têm filhos perfeitos, moram em casinhas iguaizinhas e, é claro, todos são muito felizes. Mas também existe a menção das instituições educacionais: “As crianças vão pra escola, depois pra universidade, onde entram em caixinhas e saem todas iguaizinhas", canta Nara Leão, na versão brasileira.

Vemos, através da música, uma determinada análise das relações sociais que poderia nos servir como ponto de partida para uma breve reflexão: qual seria o papel das instituições educacionais na reprodução ou transformação da ordem social? Pensando mais especificamente na universidade, como aparece nesse trecho da letra acima reproduzido, poderia ela colocar as pessoas em "caixinhas", para que saíssem todas "iguaizinhas"?

$\mathrm{Ou}$, pensando a partir dos conceitos desenvolvidos e utilizados por Antonio Gramsci e seus intérpretes, poderia a universidade difundir a 
concepção de mundo das classes trabalhadoras e ajudar a construir uma nova hegemonia? Ou ela seria apenas mais um instrumento de reprodução das sociedades capitalistas, contribuindo apenas com a manutenção da hegemonia burguesa?

Para tentar responder a essas questões, ainda que de modo bastante introdutório, é necessário resgatar alguns conceitos básicos do pensamento do teórico e militante italiano Antonio Gramsci. Isso será feito através da análise de alguns de seus escritos, mas especialmente por meio de um diálogo com alguns de seus intérpretes. Por outro lado, será abordado um aspecto do debate sobre a universidade pública brasileira, para daí se tirar alguma conclusão que possa servir de resposta às perguntas iniciais.

\section{Conceitos de Gramsci}

Em primeiro lugar, deve-se lembrar que as ideias de Antonio Gramsci, até mesmo pelas condições em que foram concebidas e organizadas (parte substancial de seus escritos foi produzida no período em que o estudioso estava preso e apenas foi organizada após a sua morte), foram recebidas das mais diferentes formas pelos intelectuais e militantes da Europa e, depois, do mundo todo. Seus escritos foram apropriados por diversas vertentes políticas e deram margem a distintas interpretações, que, não raro, são contraditórias entre si.

Além disso, cada intérprete tende a enfatizar mais um determinado conceito (muitas vezes marginalizando outros que parecem centrais nos demais estudos) explicando-o e dando-lhe um sentido bastante particular. Isso ocorre mesmo entre estudiosos de uma mesma orientação teóricometodológica, para se ter uma ideia da diversidade de interpretações sobre o pensamento de Gramsci.

Pode-se notar este fato quando Hugues Portelli mostra as diferenças de interpretação entre Norberto Bobbio, de um lado, e Jacques Texier e Luciano Gruppi, de outro, em relação à preponderância de um ou outro 
elemento (estrutura ou superestrutura) do Bloco Histórico (PORTELLI, 1997).

Entretanto, apesar de tanta controvérsia, é possível ressaltar alguns conceitos e ideias centrais no pensamento do marxista italiano, conceitos estes que devem ser discutidos inclusive para que se tenha clareza da forma como este pensamento está sendo apropriado. Aliás, deve-se deixar clara a intenção de se fazer um uso político das análises de Gramsci, ou seja, não de desenvolver um trabalho de exegese em relação aos seus escritos, exercício este de grande importância e complexidade, mas de usar seu modo de compreensão do mundo e dos problemas de seu tempo para encarar os impasses do tempo presente, especialmente aqueles que impedem as classes trabalhadoras de construir uma nova forma de organização da sociedade.

Alguns temas, portanto, aparecem como eixos centrais na obra de Gramsci, apesar de sua aparente fragmentação, como analisam Mário Maestri e Luigi Candreva:

A ideia de fragmentação emerge de uma primeira leitura dos Cadernos. [...] Porém, no emaranhado de ideias e reflexões vertidas nos Cadernos, podemos individualizar diversos fios condutores centrais, entre os quais destacam-se a 'hegemonia'; a 'questão meridional'; a 'revolução proletária'; a 'questão dos intelectuais'; o 'bloco histórico'. Entretanto, ainda que os vários argumentos abordados articulem-se fortemente, nenhum deles constitui um verdadeiro tema dominante (MAESTRI e CANDREVA, 2007, p. 237).

Além desses conceitos centrais, que funcionam como fios condutores, algumas preocupações norteiam toda a sua obra, como mostram alguns intérpretes. Uma que move fortemente o pensamento de Gramsci está relacionada às razões que levaram ao fracasso da revolução nos países capitalistas mais desenvolvidos da Europa, diferentemente do que ocorreu na Rússia. Ou, como colocam Maestri e Candreva, “A preocupação central dos Cadernos consistiu na elaboração de uma teoria da revolução válida para as 'sociedades complexas' dos países de capitalismo avançado, a partir das lições ensejadas pela revolução de outubro" (MAESTRI e CANDREVA, 2007). Desta reflexão vem toda sua discussão sobre a 
distinção entre "Oriente" e "Ocidente" no que se refere à organização social e política dos países (COUTINHO, 1993).

Esse debate sobre sociedades ocidentais ou orientais é fundamental para pensar em uma estratégia de construção de uma nova hegemonia. Quando se fala desses dois tipos distintos, não se está pensando em localização geográfica (ainda que isso possa ter dado origem aos conceitos). Para usar a explicação do próprio Gramsci: "No Oriente, o Estado era tudo, a sociedade civil era primitiva e gelatinosa; no Ocidente, havia entre o Estado e a sociedade civil uma justa relação e sob o tremor do Estado imediatamente evidenciava-se uma robusta estrutura da sociedade civil" 1 (GRAMSCI, 1980).

Uma sociedade de constituição política de tipo oriental, portanto, seria aquela que, como a Rússia de 1917, por exemplo, possui uma sociedade civil ainda em seus primórdios e desorganizada ${ }^{2}$, em que o Estado é muito fortalecido e não há grandes formas alternativas de construção de hegemonia além do assalto ao poder.

Diferente desta, uma constituição política do tipo ocidental, como os países europeus capitalistas mais desenvolvidos, na época em que Gramsci desenvolve sua análise, seria aquela em que a sociedade política, ainda que também desempenhe importante papel, já não tem tanto peso sozinha ${ }^{3}$. Ou seja, a hegemonia é construída e mantida também e principalmente pela sociedade civil, pelos organismos que a compõem. Neste caso, a religião, a opinião pública e a educação, por exemplo, têm papel fundamental na difusão da ideologia das classes dominantes e na sustentação de um determinado tipo de sociedade. Ainda que ela não possa ser mantida apenas

\footnotetext{
${ }^{1}$ Tradução nossa de todos os trechos deste mesmo texto.

2 Pensando em sociedade civil como um conjunto de "organismos privados" pelos quais as classes dominantes exercem a hegemonia, através da busca do consenso. Esses organismos podem ser, por exemplo, a imprensa, a igreja, a escola ou mesmo a família, e constituem o campo da ideologia.

3 Entende-se sociedade política como sendo um dos momentos da superestrutura (juntamente com a sociedade civil). Seria o momento da coerção, e não do exercício do consenso. Às vezes, em Gramsci, o Estado aparece como sinônimo de sociedade política, mas também pode se referir às forças armadas e ao aparato jurídico.
} 
pelo consenso, sendo necessária a coerção e atuação da sociedade política, no caso da constituição de tipo ocidental a atuação dos agentes da sociedade civil é muito mais significativa, sendo que não é possível pensar na construção de uma nova hegemonia sem passar pelo chamado bloco intelectual, sem travar uma verdadeira luta ideológica.

Portanto, a estratégia de luta a ser desenvolvida pelas classes dominadas vai depender da análise da situação concreta em que elas estão inseridas. Não é possível usar o marxismo como uma doutrina, como se ele fosse capaz de fornecer respostas prontas à luta revolucionária. O que deve ser apropriado, neste caso, é o método a ser utilizado para melhor analisar as condições em que luta deve ser travada. E Gramsci, conforme lembra Lincoln Secco, também não deixou fórmulas prontas. Segundo este intérprete, uma grande contribuição do marxista italiano foi justamente "o estudo de situações históricas concretas", o que permite que o leitor desvende seu método:

Conhecer em abstrato é metodologia estranha ao pensamento de Gramsci, ainda que haja uma dimensão abstrata do conhecimento, mas efetivamente transitória, como etapa para se chegar ao concreto. Problema significativo é o fato de que as análises de situações concretas não são generalizáveis, senão em traços essenciais, isolados apenas no nível da abstração. E quem quiser ignorar a história e derivar ações políticas de abstrações, estará condenado ao fracasso (SECCO, 2006, p. 47).

Sendo assim, não se podem generalizar as conclusões, mas utilizar os métodos, já que estes permitem, pela análise das situações concretas e da história, e da atenção às especificidades, elaborar a estratégia de ação mais eficiente. Por isso é importante a reflexão sobre o tipo de sociedade (ocidental ou oriental) de que se está falando, e sobre quais elementos da superestrutura detém mais poder neste ou naquele contexto. Como explica Portelli:

Gramsci deduziu que a estratégia das classes subordinadas deve adaptar-se à superestrutura do bloco histórico: nos países de sociedade civil forte, a luta só pode assumir a forma de uma "guerra de posições": o 
Estado (sociedade política) não é mais que uma "trincheira avançada, atrás da qual se encontra uma poderosa cadeia de fortalezas e casamatas" (a sociedade civil) $[\ldots]$

Nos países em que, como a Rússia em 1917, a sociedade civil é "primitiva e gelatinosa", a luta é, ao contrário, essencialmente política e militar e deve, por isso, adotar a forma de uma "guerra de movimentos" (PORTELLI, 1977, p. 119).

Mas não se pode pensar nesses conceitos, como lembra Coutinho, "geograficamente", como já explicado, ou de forma estática, mas sim como formações sociais que são resultado de um processo histórico. Desta forma, alguns países ocidentais podem ter se formado com características chamadas orientais, em sua gênese política, e sofrido um processo de ocidentalização, agregando seus "pressupostos objetivos".

Pensando no caso específico do Brasil, que é o contexto em que estamos inseridos, pode-se resgatar a análise de Coutinho sobre esse processo de "ocidentalização". Esse autor explica, observando a história política brasileira, que a Revolução de 30 foi uma espécie de Revolução Passiva: ao mesmo tempo em que foi um movimento para impedir uma transformação radical de "baixo para cima", com ampla participação popular (sendo nesse sentido, uma "restauração"), também representou uma "renovação", pois pôde assimilar muitas demandas populares. Ou seja, a modernização e o desenvolvimento do capitalismo no Brasil foram executados pelo Estado e pelas elites, com a utilização dos aparelhos repressivos, e através da exclusão das forças populares, sem uma revolução “democrático-burguesa", com um radicalismo jacobino.

E, pensando na Revolução Passiva como um movimento que se dá não só na consolidação do capitalismo, mas também na passagem do capitalismo de sua fase concorrencial para a fase monopolista, pode-se também melhor entender os objetivos do regime militar instalado no Brasil em 1964: a estrutura agrária foi transformada, ainda que se tenha conservado o latifúndio, e houve o reforço do princípio do lucro privado e 
do poder das classes dominantes (burguesia industrial e financeira, e latifundiários capitalistas).

Com o regime militar, uma tendência de fortalecimento da sociedade civil brasileira, verificada entre os dois períodos autoritários (1945-1964), foi freada e a relação entre ela e o Estado foi desequilibrada. Entretanto, os diversos movimentos sociais começaram a se organizar e a se fortalecer a partir de meados dos anos 70, tendo importante peso o movimento para eleição direta para a Presidência da República.

Dessa forma, constata-se, como explica Coutinho, um aparente paradoxo: o do fortalecimento da sociedade civil e do processo de ocidentalização da organização política brasileira durante um regime ditatorial. E o autor continua argumentando que isso foi possível porque o regime brasileiro nunca foi uma ditadura fascista clássica, precisando tolerar a presença de um Parlamento e de alguma oposição para a garantia de um consenso mínimo.

Contribuiu para seu colapso também a crise do chamado Milagre Econômico, o que acabou minando ainda mais as suas bases de consenso:

No contexto dessa profunda crise de legitimação, os aparelhos da sociedade civil puderam de novo voltar à luz, hegemonizados agora por um amplo arco de forças antiditatoriais, que ia da esquerda aos conservadores "esclarecidos", ainda que com predominância desses últimos. O "feiticeiro" desencadeara forças que já não podia controlar. Pondo em prática uma política econômica fortemente modernizadora, a ditadura promoveu um espetacular desenvolvimento das forças produtivas: sob a égide de uma "revolução-restauração", o Brasil ingressou na fase do capitalismo monopolista de Estado. E essa modernização, mesmo sendo "conservadora" [...], consolidou de modo irreversível os pressupostos objetivos da "ocidentalização" da sociedade brasileira (COUTINHO, 1993, p. 125).

Mesmo assim, apesar de o Brasil ter se tornado um país ocidental (por uma Revolução Passiva), ainda existe um longo caminho a se trilhar para se fortalecer e se consolidar a sociedade civil brasileira e formar de fato uma democracia de massas, que possa colocar o país no caminho para o socialismo, ainda segundo Carlos Nelson Coutinho. E é neste ponto que 
entra a importância da chamada guerra de posições para a conquista da hegemonia por parte das classes dominadas.

Em um país como o Brasil, de características ocidentais, não se pode apostar (como a esquerda tradicional antigamente apostava) apenas em um embate direto com os aparelhos de coerção do Estado. Ao contrário, deve-se empreender uma guerra de posições, na intenção de "conquistar" primeiro a sociedade civil, através da batalha ideológica. Nesse contexto, a guerra de movimento não seria totalmente deixada de lado, mas teria uma função complementar e posterior, sendo o Estado apenas uma "trincheira avançada", para usar um termo do próprio Gramsci.

Adotar o confronto direto com a sociedade política não seria, desse ponto de vista, apenas um equívoco estratégico resultante de uma má interpretação teórica, mas poderia ter graves consequiências para a luta das classes subalternas, pois além de exigir grande sacrifício destas, ainda poderia provocar uma vigorosa reação das classes dominantes, capaz de imobilizar por longos períodos e de várias formas a construção da resistência e da superação.

Por isso, é preciso analisar com cuidado quais são as condições e meios de organização e luta. Por exemplo, Gramsci lembra, em suas Notas sobre Maquiavel, que as crises estruturais não são suficientes para que as classes subalternas possam obter sucesso "automático", como defendia um certo economicismo determinista:

Como ocorria na guerra, quando um encarniçado fogo de artilharia parecia ter destruído todo o sistema defensivo do adversário, mas, na realidade, só o atingira na sua superfície externa, e no momento do ataque e do avanço os assaltantes defrontavam-se com uma linha defensiva ainda eficiente, o mesmo ocorre na política durante as grandes crises econômicas. Nem as tropas atacantes, por efeito da crise, organizam-se rapidamente no tempo e no espaço, nem muito menos adquirem um espírito agressivo; reciprocamente, os atacados não se desmoralizam, nem abandonam as defesas, mesmo entre ruínas, nem perdem a confiança na sua força e no seu futuro (GRAMSCI, 1980, p. 81). 
Nas sociedades ocidentais, as crises econômicas (estruturais) poderiam servir ou não como artilharia eficiente contra as classes dominantes dependendo da organização dos combatentes e de sua atuação no nível superestrutural (batalha ideológica), já que estes dois níveis se sustentam mutuamente, mantendo coeso o Bloco Histórico. Melhor dizendo, apenas a ocorrência de uma crise econômica não seria capaz de minar o poder estabelecido, porque o Bloco Histórico não se compõe apenas da estrutura, mas também da superestrutura ideológica, que emerge, nesses momentos de ataque, como um poderoso complexo que, além de permanecer ileso ou praticamente intacto, ainda é capaz de manter a organização social durante a reestruturação econômica.

E isso porque, como mostra Portelli, os elementos do Bloco Histórico não possuem pesos desiguais. A discussão sobre a primazia da estrutura ou da superestrutura coloca, segundo este autor, um falso problema, pois Gramsci nem mesmo as considera separadamente. O verdadeiro ponto seria o do "vínculo orgânico" entre esses dois momentos, e a compreensão da natureza dessa relação é de fundamental importância para a possibilidade de construção de um novo Bloco Histórico (PORTELLI, 1977).

Entretanto, como mostra Gramsci, essa organização não é tão sólida que não possa ser superada. Aliás, é preciso cuidado ao se falar em sociedade civil como espaço de difusão das ideologias das classes dominantes. Ainda que isso seja real, não se trata de um caminho de mão única, mas de um espaço de lutas, em que há tentativas de difusão ou imposição de uma concepção de mundo, mas em que também há resistências e, mais que isso, a construção de concepções de mundo diversas e inclusive antagônicas às dominantes. Nesse sentido, a sociedade civil é também onde ocorre um embate constante pela manutenção ou destruição do Bloco Histórico.

Portanto, o que se mostra necessário, nesse contexto, como já dito, é compreender profundamente como se mantém o poder das classes dominantes, ou como se construiu e se sustenta a hegemonia em uma 
determinada sociedade. Ou, como coloca Terry Eagleton, ao discutir a hegemonia:

Como a classe operária assumirá o poder em uma formação social em que o poder dominante está sutil e difusamente presente em todas as práticas habituais diárias, intimamente entrelaçado com a própria 'cultura', inscrito na própria textura de nossa experiência, da préescola ao salão do velório? Como combatemos um poder que se tornou o 'senso comum' de toda uma ordem social em vez de um poder que é amplamente percebido como alheio e opressivo?

$\mathrm{Na}$ sociedade moderna, então, não é suficiente ocupar fábricas ou entrar em confronto com o Estado. $\mathrm{O}$ que também deve ser contestado é toda a área de 'cultura', definida em seu sentido mais amplo, mais corriqueiro (EAGLETON, 1997).

O autor chama a atenção, portanto, para o peso da sociedade civil e da cultura, entendida aqui de forma ampla, em um determinado contexto e, para retomar esse ponto da discussão, é necessário analisar e compreender, em cada situação específica, quais são seus organismos mais poderosos, influentes e desenvolvidos.

Ou seja, apenas constatar que o Brasil é uma sociedade do tipo ocidental é importante, mas não é suficiente, porque não nos permite usar as mesmas conclusões tiradas de contextos de outros países capitalistas modernos. E isso porque cada país tem particularidades em sua formação histórica e também na composição e equilíbrio de sua superestrutura. Mais que isso, os próprios organismos que constituem a sociedade civil podem ter significados distintos nas mais variadas situações.

Voltando ao conceito de sociedade civil, explica Carlos Nelson Coutinho que nela se elaboram e difundem as ideologias por organizações como o sistema escolar, as Igrejas, os partidos, sindicatos, meios de comunicação em massa, editoras, etc. (COUTINHO, 2007). Tendo o Brasil uma sociedade civil desenvolvida, é possível compreender, portanto, por onde deve passar a luta das classes subalternas para alcançar uma organização social alternativa. Mas, como já dito, é também preciso analisar quais desses organismos são os mais sólidos na constituição basilar do 
Bloco Histórico e os mais eficientes na difusão da ideologia, pois é nesses espaços que deve se dar a disputa e o fortalecimento das classes subordinadas. Como assinalam Maestri e Candreva, "a classe que pretende conquistar o poder deve, necessariamente, impor a sua hegemonia sobre os mais amplos setores da população, antes de exercitar sua ditadura" (MAESTRI e CANDREVA, 2007, grifo meu).

Isso significa, portanto, disputar os espaços de exercício da hegemonia e buscar também difundir a concepção de mundo das classes subalternas. Porém, não se trata de colocar a luta para fora do Estado, como pretendeu Althusser, segundo Coutinho, mas sim de preceder a conquista de poder do Estado "por uma longa batalha pela hegemonia e pelo consenso no interior e através da sociedade civil, isto é, no interior do próprio Estado em seu sentido amplo" (COUTINHO, 2007).

\section{A universidade e uma nova hegemonia}

Sendo assim, e chegando de fato à reflexão proposta no início do texto, pode-se entender que, no caso brasileiro, o sistema escolar de todos os níveis tem a sua participação como organismo da sociedade civil que formula e difunde a ideologia das classes dominantes e, portanto, ajuda a manter a coesão social e a existência do Bloco Histórico.

Talvez ela não seja o organismo mais poderoso, desenvolvido e influente de nossa sociedade (cabendo talvez à mídia esse papel), mas através da educação são transmitidos (com a possibilidade de serem também construídos), além da cultura em si à qual se pertence, valores, disciplina, respeito à hierarquia, e uma série de habilidades e códigos de comportamento a serem utilizadas no mundo do trabalho e nas relações sociais de modo geral.

Pela sua estrutura atual, as instituições educacionais, em todos os níveis, servem mais à reprodução do que à construção de uma alternativa social, mas isso depende da luta travada pelos agentes nesses espaços. 
Gramsci destacava esse processo em seu escrito Para a investigação do princípio educativo:

A marca social é dada pelo fato de que cada grupo social tem um tipo de escola próprio, destinado a perpetuar nestes grupos uma determinada função tradicional, diretiva ou instrumental. Se se quer destruir esta trama, portanto, deve-se evitar a multiplicação e graduação dos tipos de escola profissional, criando-se, ao contrário, um tipo único de escola preparatória (GRAMSCI, 1979, p. 136).

As classes dominantes vão sempre lutar por uma estrutura educacional que seja capaz de manter e reproduzir a ordem social, criando tipos de escolas específicos para cada nível. E, evidentemente, essa estrutura será sempre envernizada com um discurso democrático, como lembra Gramsci mais adiante.

Esse mesmo raciocínio pode ser encontrado, olhando mais diretamente para o tema do presente trabalho, na crescente tendência à diversificação da educação superior. Simon Schwartzman, sociólogo brasileiro e um dos defensores do privatismo, da avaliação e da diferenciação no ensino superior brasileiro, por exemplo, argumenta, falando sobre práticas de avaliação:

No Brasil, ainda prevalece a ideia de que todo o ensino superior deve ser dado em universidades públicas, que os professores devem ser pesquisadores e trabalhar em regime de tempo integral, e que os estudantes devem também se dedicar primordialmente ao estudo e ser avaliados pelos critérios dos professores das instituições mais privilegiadas. E no entanto, a grande maioria das instituições são privadas, a maioria dos professores só praticam o ensino, a maioria dos alunos estudam à noite $\mathrm{e}$ trabalham durante o dia, e poucos chegam ao ensino superior com condições de atender tais requisitos acadêmicos dos cursos mais exigentes (SCHWARTZMAN, 2008, p. 3).

Este autor, ainda que abordando especificamente a questão da avaliação do ensino superior, simboliza de forma bastante interessante a concepção das classes dominantes e dirigentes sobre o que e para que deva ser a educação, por isso não é necessário aqui fazer um resgate exaustivo desse debate, mas apenas usar este exemplo para o início de uma reflexão. 
Schwartzman critica a avaliação da educação superior no Brasil, mas não pelos seus pressupostos básicos (os de utilizar para as áreas da educação, cultura e conhecimento um raciocínio empresarial e mercadológico, que busca produtividade e competitividade), mas pelo fato de ela não ser suficientemente justa com as instituições privadas de ensino. Nessa e em outras ocasiões, o autor argumenta que estas faculdades e universidades geralmente têm baixo desempenho nas avaliações porque contam com imensas desvantagens em relação às instituições públicas, a começar pelo nível da formação anterior de seus alunos. Por isso, não seria justo que elas fossem avaliadas da mesma forma, sem levar em conta essas desvantagens, pois assim não se estaria medindo sua qualidade com segurança.

Além disso, com a atual estruturação da educação superior brasileira, fica bastante claro que neste nível existem instituições com diversas finalidades: algumas com atividades de ensino, pesquisa e extensão, como é o caso das universidades, e outras voltadas apenas ao ensino, o que costuma ocorrer geralmente nas faculdades isoladas, em que nem estudantes nem mesmo professores realizam atividades de pesquisa. Por isso, não seria adequado aplicar as mesmas cobranças para todas elas, através de avaliações que, em geral, partem do modelo de universidade pública de nível excelente, já que elas formam uma infinidade de instituições que possuem funções diferentes.

O que interessa aqui é notar que essas diferenças existentes no ensino superior não seriam algo a ser contornado. Existe o reconhecimento de que há um desnível de qualidade e de funções mas, mais que isso, de que essa situação é algo "natural” no atual estágio de desenvolvimento de nossa sociedade. Ou seja, há universidades em que os professores trabalham com dedicação integral e em que os alunos podem se dedicar mais aos estudos, e há aquelas em que a maioria dos alunos trabalha e a maioria dos professores não realiza pesquisa, e esse desenho educacional é mais do que normal porque reflete bastante bem a estrutura social em que está inserido. 
Em outras palavras, a diferenciação institucional seria necessária porque a sociedade é "diferenciada" (termo que elegantemente substitui a palavra "desigual"). Sendo assim, é evidente que existam instituições de simples preparação superficial e ligeira de profissionais para ocupar postos bastante inferiores no mercado de trabalho ou até para a informalidade, e vários graus de formação até chegar às chamadas "ilhas de excelência", direcionadas para as classes sociais aliadas e dominantes.

E vale destacar como esse argumento é revestido com uma retórica democrática, já que nele se demonstra uma preocupação com a justiça e a confiabilidade da avaliação, além de se apontar para o papel da diferenciação e da privatização na ampliação do acesso e na geração de vagas para as populações menos favorecidas econômica e culturalmente.

Ora, se o que se busca é uma sociedade menos desigual, como aparece na retórica destes autores (intelectuais orgânicos das classes dominantes, para usar a categoria de Gramsci), como compactuar com um sistema educacional que só tende a reforçar essas desigualdades? Como afirma o marxista italiano na passagem já citada, para destruir essa trama de reprodução, seria preciso criar um "tipo único de escola preparatória". Ainda que neste momento Gramsci esteja se referindo à educação elementar/média, vale lembrar que o que está em jogo é já uma formação que atende a uma demanda do mundo do trabalho. Atualmente, sabe-se que, ainda que a grande maioria da população brasileira esteja fora da educação superior, e boa parte esteja ainda fora do próprio ensino médio, existe uma pressão cada vez maior por parte do mercado de trabalho no sentido de exigir uma qualificação superior e específica para muitas áreas. Portanto, a análise de Gramsci se mostra fundamental também para a discussão sobre o papel da educação superior hoje.

A universalização da educação, segundo a perspectiva gramsciana, é de extrema importância para que as classes subalternas possam ter acesso à cultura geral, universal, inclusive à cultura burguesa, para que se ampliem seus horizontes de conhecimento, percepção e reflexão sobre o mundo e as relações sociais. A apropriação da história, da filosofia, das ciências e 
também das técnicas relativas ao mundo da produção (sendo aqui a educação identificada com o trabalho) é primordial para que os trabalhadores tenham condições de se organizar e para que "cada cidadão possa se tornar 'governante' (GRAMSCI, 1979).

O ensino aqui, mesmo o profissional, não é visto somente no sentido de garantir a possibilidade de ascensão social do indivíduo, mas de possibilitar uma visão ampla da sociedade e dos impasses de sua própria classe, para que se possa captar as contradições sociais e encontrar nelas mesmas as respostas para sua emancipação. Evidentemente, esse momento de conscientização, para além dos interesses corporativos, ou a catarse de que fala Gramsci, não se dá separadamente na estrutura ou na superestrutura, mas se faz na luta pela concepção e imposição de um projeto próprio das classes subalternas de sociedade.

Essa educação ampla, sólida, em suma, integral, capaz de colocar o ser humano no centro das preocupações de uma formação ao mesmo tempo profissional, científica e humanista, e não as demandas do capital, é vista como fundamental para o enfrentamento da chamada "guerra de posições" da sociedade ocidental, como coloca Giovanni Semeraro (SEMERARO, 2007).

E a educação superior, neste sentido, deve ser reivindicada pelas classes trabalhadoras em sua amplitude, ou seja, como uma educação pública, gratuita, laica, de qualidade e universitária. Destaca-se aqui que ela seja universitária porque apenas esta garante a pesquisa e a extensão como suas características basilares, e é justamente a pesquisa que fornece ao estudante, em sua formação, a capacidade de descobrir, interpretar e recriar o mundo em que vive, de analisar criticamente e organizar de modo ativo sua relação com a sociedade.

Por outro lado, a extensão também deve ser visada, não para que a universidade se torne uma prestadora de serviços para o setor produtivo, mas uma solucionadora dos problemas humanos, do drama das grandes cidades com suas misérias a catástrofes, das tragédias da falta de saúde. E, mais que isso, para além da ideia de uma simples "extensão", que leva o 
conhecimento de uma fonte de luz para solucionar os problemas da escuridão, vista como sinônimo de ausência total de razão, a universidade deveria manter a "comunicação" com as pessoas da comunidade, para construir junto com ela alternativas e uma sociedade mais igualitária, como defendia Paulo Freire (FREIRE, 2001). Essa comunicação também poderia cumprir essencial papel de elevação cultural das massas, através não só do acesso, mas também da possibilidade de participação da própria criação e recriação da cultura.

A pesquisa no nível superior, para os docentes e discentes, tem grande importância também para a formação dos futuros professores da educação básica, pois sua atuação crítica e amplamente consciente (e não simplesmente corporativa) poderá ser refletida de maneira positiva na trajetória educacional dos jovens (lembremos da responsabilidade do professor apontada por Gramsci ao falar de suas experiências em seus escritos sobre a cultura).

Sendo assim, e para retomar a versão brasileira da canção de Malvina Reynolds, e pensando em toda a reflexão feita até aqui, poderia a universidade colocar as pessoas em "caixinhas", para que saiam todas “iguaizinhas"? Bem, esse seria o ideal de instituição das classes dominantes, especialmente das instituições educacionais, pois não abririam possibilidade para resistência de qualquer tipo, em época nenhuma da história, tendo apenas o papel de perfeitas e mecânicas reprodutoras da engrenagem social.

Entretanto, todos os espaços sociais são ocupados por pessoas que trabalham, estudam, pensam, sofrem, relacionam-se, em suma, vivem e transformam o mundo a todo o momento, mesmo com a mais aparentemente ínfima das atitudes, e ainda que de forma "inconsciente", ou seja, sem reflexão ou sem a intenção de alcançar tal ou qual objetivo.

Mais do que viver, as pessoas lutam. "A história de todas as sociedades até hoje existentes é a história das lutas de classes", já afirmavam Marx e Engels, no fim do século XIX (MARX e ENGELS, 1998), e esta luta está presente em todos os âmbitos das relações sociais. Dessa forma, existem momentos em que as classes dominantes possuem 
maior capacidade de neutralizar a luta e a resistências das classes subalternas, como os momentos de regimes autoritários. Ainda assim, nunca é possível que exista uma neutralização total, o que significaria o fim da História.

Ao contrário, é sempre possível, e de certa forma até inevitável, dadas as contradições inerentes ao sistema capitalista, que se busquem novas armas, que se encontrem novos aliados e se abram novas trincheiras para que se quebrem as "caixinhas" e se libertem a si mesmas as pessoas não mais para a reprodução do mesmo, mas para a construção de uma alternativa, livre e igualitária forma de organização da sociedade.

\section{Referências bibliográficas}

COUTINHO, C. N. As categorias de Gramsci e a realidade brasileira. In. COUTINHO, C. N., NOGUEIRA, M. A. (org.) Gramsci e a América Latina. Rio de Janeiro: Paz e Terra, 1993.

COUTINHO, C. N. Gramsci. Um estudo sobre seu pensamento político. Rio de Janeiro: Civilização Brasileira, 2007.

EAGLETON, T. Ideologia. Uma introdução. São Paulo: Editora Unesp e Boitempo, 1997.

FREIRE, P. Extensão ou comunicação? São Paulo: Paz e Terra, 2001.

GRAMSCI, A. Os intelectuais e a organização da cultura. Rio de Janeiro: Editora Civilização Brasileira, 1979.

GRAMSCI, A. Notas sobre Maquiavelo, sobre la politica y sobre el Estado moderno. Madrid: Ediciones Nueva Visión, 1980.

MAESTRI, M e CANDREVA, L. Antonio Gramsci: vida e obra de um comunista revolucionário. São Paulo: Expressão Popular, 2007.

MARX, K.; ENGELS, F. O manifesto comunista. São Paulo: Boitempo, 1998.

PORTELLI, H. Gramsci e o Bloco Histórico. Rio de Janeiro: Paz e Terra, 1977.

SCHWARTZMAN, S. O 'conceito preliminar' e as boas práticas de avaliação do ensino superior. Revista da Associação Brasileira de Mantenedoras de Ensino Superior, n. 38, Dezembro de 2008.

SECCO, L. Gramsci e a Revolução. São Paulo: Alameda, 2006. 
SEMERARO, G. Da libertação à hegemonia: Freire e Gramsci no processo de democratização do Brasil. Curitiba: Revista de Sociologia e Política, 2007. 